\title{
Optimizing Caries Prevention Program in Dental Practice Based on Human Development Index (HDI): A Systematic Review
}

\author{
Regina Widjaja ${ }^{1}$, Putri Durotun Nafisa ${ }^{1}$, Clarabella Shakeena Aribowo ${ }^{1}$, Ivana Abigayl ${ }^{2}$ \\ ${ }^{1}$ Faculty of Dentistry, Maranatha Christian University, Indonesia \\ ${ }^{2}$ Department of Public Health, Faculty of Dentistry, Maranatha Christian University, Indonesia
}

\begin{abstract}
Objective: Oral health must be maintained from an early age to reduce the number of dental and oral diseases. According to the Basic Health Research (2018), which was conducted by the National Institute of Health Research and Development (NIHRD), Ministry of Health Indonesia, the prevalence of caries in Indonesia is $88.8 \%$. Caries prevention programs are aimed at citizens in various countries. Hence, in formulating the programs, many aspects must be taken into account, such as health, education, and economy, which are related to the Human Development Index (HDI). This review aims to find effective caries prevention programs in various countries, especially in Indonesia.

Methods: The review is written based on 22 online articles, which were published from 2017 to 2021, with the keyword "caries prevention" in PubMed.

Results: Based on previous research, three aspects that are related to HDI (health, education, economy) are influencing caries prevention programs that are being implemented in various countries. Countries with very high HDI (above 0.799) are dominantly implementing the application of fluorides and antimicrobials to prevent caries. Contrastingly, countries with high HDI (0.700-0.799) and medium HDI (0.550-0.699), one of which is Indonesia, dominantly choose dental health education to prevent caries.

Conclusions: HDI of a country can be used as a benchmark for determining caries prevention programs in order to optimize caries prevention programs.
\end{abstract}

Keywords: Caries, caries prevention program, Human Development Index, Indonesia

Copyright (C) 2021. Korean Academy of Preventive Dentistry. All rights reserved.

This is an Open Access article distributed under the terms of the Creative Commons Attribution Non-Commercial License (http://creativecommons.org/licenses/ by-nc/4.0) which permits unrestricted non-commercial use, distribution, and reproduction in any medium, provided the original work is properly cited. 